\title{
MicroRNA-182-5p contributes to the protective effects of thrombospondin 1 against lipotoxicity in INS-1 cells
}

\author{
YING LIU ${ }^{1,2}$, JIAYUE DONG ${ }^{3}$ and BO REN ${ }^{3}$ \\ ${ }^{1}$ Department of Pediatrics, West China Second University Hospital, Sichuan University; ${ }^{2}$ Laboratory of Birth Defects \\ and Related Disease of Women and Children, Sichuan University, Ministry of Education, Chengdu, Sichuan 610041; \\ ${ }^{3}$ Department of Traditional Chinese Medicine, College of Pharmacy, Chengdu University, Chengdu, Sichuan 610106, P.R. China
}

Received March 2, 2018; Accepted July 26, 2018

DOI: $10.3892 /$ etm.2018.6883

\begin{abstract}
The dysfunction of beta cells serves an important role in the pathogenesis of type 2 diabetes mellitus (T2DM). An improved understanding of the molecular mechanisms underlying beta cell mass and failure will be useful for identifying novel approaches toward preventing and treating this disease. Recent studies have indicated that free fatty acids (FFAs) can cause beta cell dysfunction. In the present study, palmitate (Pal) was used as a FFA and its functions on cell viability and apoptosis were detected. MTT assay and flow cytometry were used and the results revealed that incubation of INS-1 cells with Pal significantly decreased cell viability and increased cell apoptosis. However, a co-incubation with thrombospondin 1 (THBS-1) protected the cells against Pal-induced toxicity. Numerous studies have demonstrated that microRNAs (miRs) are involved in fatty acid-induced beta cell dysfunction. Various studies have reported that miR-182-5p is associated with a number of diseases, including cancer, heart disease, and leukemia. However, to the best of our knowledge miR-182-5p has never been reported to be associated with diabetes. In the present study, miR-182-5p, which is predicted to target the 3'-untranslated region (UTR) of THBS-1, was detected using reverse transcription-quantitative polymerase chain reaction in INS-1 cells in response to Pal. miR-182-5p was significantly increased in Pal-treated cells compared with the control cells. Furthermore, miR-182-5p mimics significantly decreased cell viability and increased Pal-induced apoptosis in INS-1 cells. However, cell viability was increased and Pal-induced apoptosis was decreased in cells that were treated with miR-182-5p
\end{abstract}

Correspondence to: Professor Bo Ren, Department of Traditional Chinese Medicine, College of Pharmacy, Chengdu University, 1166 Liutai Road, Wenjiang, Chengdu, Sichuan 610106, P.R. China E-mail: renbo_chengdu2008@163.com

Abbreviations: miRs, microRNAs; T2DM, type 2 diabetes; RT-qPCR, reverse transcription-quantitative polymerase chain reaction; FFAs, free fatty acids

Key words: microRNAs, diabetes, palmitate, apoptosis, beta cells inhibitors. The present findings also revealed that overexpression of THBS-1 counteracted the effect of miR-182-5p on cell viability and apoptosis. These results suggested that miR-182-5p is involved in the mechanism of THBS 1 on the modulation of beta cell survival.

\section{Introduction}

Diabetes is one of the most important non-communicable diseases worldwide (1). According to the International Diabetes Federation statistics, the number of patients with diabetes worldwide in 2011 reached 370 million, and this number will be nearly 550 million by 2030 . T2DM is a progressive disease caused by insulin resistance and/or beta cell dysfunction, which results in relative insulin deficiency. The reduction in beta cell mass and beta cell dysfunction contribute toward the pathological process (2). A previous study has suggested that beta cell dysfunction in patients with clinical manifestations of T2DM may have begun 15 years previously (2). Increased levels of circulating free fatty acids (FFAs) have been indicated to cause defective beta cell proliferation and increased beta cell apoptosis. Therefore, lipotoxicity has an important role in the pathogenesis of T2DM (3).

THBS-1 is an extracellular matrix-bound factor and was reported as the first naturally occurring inhibitor of angiogenesis (4). It was also revealed to be involved in other processes, including regulation of extracellular matrix function, blood clot formation and the immune response (5-7). Recently, accumulating research has suggested that THBS-1 is associated with T2DM and beta cell function (8-10).

MicroRNAs (miRs) are 19 to 22-nucleotide noncoding RNAs that can regulate cell survival, cell function, apoptosis and differentiation by suppressing the transcription of mRNA (11-13). Currently, extensive research has suggested that miRs are involved in fatty acid-induced beta cell dysfunction (14-16). miR-182-5p, which has been predicted to target THBS-1, has been confirmed to participate in the progression of various diseases, including cancer (17), ischemia-reperfusion injury (18) and leukemia (19). However, to the best of our knowledge miR-182-5p has not been reported to be associated with T2DM or beta cell function.

The present study aimed to identify whether palmitate (Pal) impacted the viability and apoptosis of INS-1 cells. 
Reverse transcription-quantitative polymerase chain reaction (RT-qPCR) was performed to assess the THBS-1 mRNA expression levels in Pal-treated cells compared with the control cells. Subsequent MTT and flow cytometry assays were also performed. The present study provided an insight into whether miR-182-5p may participate in the protective effects of THBS-1 against lipotoxicity in INS-1 cells, and whether it may be a novel biomarker for the diagnosis and treatment of T2DM.

\section{Materials and methods}

Cell culture. Rat INS-1 cells (Shanghai Fushan Industrial Co., Ltd, Shanghai, China) were cultured in RPMI 1640 medium (Gibco, Thermo Fisher Scientific, Inc., Waltham, MA, USA), containing $11 \mathrm{mmol} / 1$ glucose, $10 \%$ fetal bovine serum (Gibco, Thermo Fisher Scientific, Inc.), $1 \mathrm{mmol} / 1$ sodium pyruvate, $2 \mathrm{mmol} / \mathrm{l}$ glutamine, $10 \mathrm{mmol} / 1 \mathrm{HEPES}, 55 \mu \mathrm{mol} / \mathrm{l}$ beta-mercaptoethanol, $100 \mathrm{IU} / \mathrm{ml}$ penicillin and $100 \mu \mathrm{g} / \mathrm{ml}$ streptomycin at $37^{\circ} \mathrm{C}$ containing $5 \% \mathrm{CO}_{2}$.

Vector constructions and miR transfection. The coding sequence of THBS-1 was cloned into a pcDNA3 vector, prior to the construction of the THBS-1 expression plasmid, pcDNA3-THBS-1. The enhanced green fluorescent (EGFP) coding region from the pEGFP-N2 vector was cloned into pcDNA3 to form pcDNA3-EGFP, and the wild-type or mutant-type THBS-1 3'-UTR was amplified and cloned into the pcDNA3-EGFP vector. A total of $20 \mu \mathrm{M}$ miR-182-5p mimics, inhibitors and the corresponding control (miR-NC) (Shanghai GenePharma Co., Ltd., Shanghai, China) were transfected into INS-1 cells using Lipofectamine 2000 reagent (Invitrogen; Thermo Fisher Scientific, Inc.) according to the manufacturer's instructions. The sequences used were as follows: miR-182-5p, 5'-UUUGGCAAUGGUAGAACUCAC ACCG-3'; miR-182-5p inhibitor, 5'-CGGUGUGAGUUCUAC CAUUGCCAAA-3'; and miR-NC, 5'-UUGUACUACACA AAAGUAGUC-3'. Following $24 \mathrm{~h}$ of transfection, the subsequent experiments were carried out.

FFA treatment. Pal (Sigma-Aldrich; Merck KGaA, Darmstadt, Germany), which was used as the FFA, was dissolved into $0.01 \mathrm{~mol} / 1 \mathrm{NaOH}$ to a concentration of $100 \mathrm{mmol} / \mathrm{l}$. Subsequently, the solution was diluted in RPMI-1640 medium and mixed with $0.5 \%$ FFA-free bovine serum albumin (Gibco; Thermo Fisher Scientific, Inc.) for $30 \mathrm{~min}$ at $55^{\circ} \mathrm{C}$. INS-1 cells were cultured and exposed at $37^{\circ} \mathrm{C}$ to $\mathrm{Pal}(0.25,0.5$, and $1.0 \mathrm{~mol} / \mathrm{l}$ ) for 8,24 or $48 \mathrm{~h}$. The control cells were treated with equivalent concentrations of $\mathrm{NaOH}$.

MTT assay. INS-1 cells were transfected with plasmids, miR-182-5p mimics or inhibitors. A total of $8 \times 10^{3}$ cells were placed into 96 -well culture plates for $24 \mathrm{~h}$ at $37^{\circ} \mathrm{C}$. Cells were incubated with different concentrations of $\mathrm{Pal}(0.25,0.5$ and $1.0 \mathrm{mmol} / \mathrm{l}$ ) for a further $24 \mathrm{~h}$. A total of $10 \mu \mathrm{l}$ of MTT (5 mg/ml; Sigma-Aldrich; Merck KGaA) was added into the wells and the cells were incubated for $4 \mathrm{~h}$ at $37^{\circ} \mathrm{C}$. The culture plate was centrifuged at $225 \mathrm{x}$ g for $5 \mathrm{~min}$ at room temperature and the supernatant was removed. Following this, $150 \mu 1$ dimethyl sulfoxide (Sigma-Aldrich; Merck KGaA) was added to the medium of each well and the plate was placed on a shaker in the dark for $20 \mathrm{~min}$ at room temperature. Finally, the absorbance value of each well at the wavelength of $570 \mathrm{~nm}$ (A570) was measured.

Apoptosis assay. An annexin V-fluorescein isothiocyanate (FITC)/propidium iodide (PI) apoptosis detection kit (BD Biosciences Medical Devices Shanghai Co., Ltd., Shanghai, China) was used to detect INS-1 cell apoptosis. Cells were collected following centrifugation at room temperature for $10 \mathrm{~min}$ at $225 \mathrm{x} \mathrm{g}$, washed with phosphate buffered saline and resuspended in binding buffer $(300 \mu \mathrm{l})$. A total of $5 \mu \mathrm{l}$ annexin V-FITC solution was added, followed by incubation at room temperature for $15 \mathrm{~min}$ in the dark. Finally, $5 \mu \mathrm{l}$ PI was added to the cell suspension. A flow cytometer (BD Bioscience, Shanghai, China) was used to analyze cell apoptosis. Among the analyzed cells, FITC ${ }^{-} / \mathrm{PI}^{-}$cells represented healthy living cells, $\mathrm{FITC}^{+} / \mathrm{PI}^{-}$cells indicated early apoptotic cells and $\mathrm{FITC}^{+} / \mathrm{PI}^{+}$cells represented necrosis and late apoptotic cells.

RT-qPCR analysis. TRIzol reagent (Invitrogen; Thermo Fisher Scientific, Inc) and the mirVana miRNA Isolation Kit (Ambion; Thermo Fisher Scientific.) were used to extract total RNA and miRs. The oligo-dT or stem-loop reverse transcriptase primers were used to obtain cDNA. PCR was performed using the SYBR Premix Ex Taq (Takara Biotechnology Co., Ltd., Dalian, China) to detect the expression levels of THBS-1 mRNA and miR-182-5p. $\beta$-actin and U6 were used as the corresponding controls. The primer sequences used in the present study are indicated in Table I. The reaction conditions used were as follows: $94^{\circ} \mathrm{C}$ for $5 \mathrm{~min}$, followed by 40 cycles of $94^{\circ} \mathrm{C}$ for $1 \mathrm{~min}, 56^{\circ} \mathrm{C}$ for $1 \mathrm{~min}$ and $72^{\circ} \mathrm{C}$ for $1 \mathrm{~min}$. The relative expression levels were calculated using the $2^{-\Delta \Delta \mathrm{Cq}}$ method (20).

Western blot analysis. Cells were transfected with miR-182-5p mimics or inhibitors. Protein concentration was determined by bicinchoninic acid assay. Cell protein samples were obtained using radioimmunoprecipitation assay lysis buffer (Beijing BLKW Biotechnology Co., Ltd, Beijing, China), separated by $8 \%$ SDS-PAGE $(20 \mu \mathrm{g} /$ lane $)$ and transferred to nitrocellulose membranes. Following this, samples were blocked with $5 \%$ skimmed milk for $2 \mathrm{~h}$ at room temperature. Membranes were incubated with anti-THBS-1 antibody (ab88529; 1:200; Abcam, Cambridge, MA, USA) and anti-GAPDH antibody (ab8245; 1:500; Abcam) overnight at $4^{\circ} \mathrm{C}$. Subsequently, the horseradish peroxidase-conjugated corresponding immunoglobulin G (ab7090; 1:1,000; Abcam) was added for incubation at room temperature for $2 \mathrm{~h}$. The protein expression level was assessed using an enhanced chemiluminescence regent (Santa Cruz Biotechnology, Inc., Dallas, TX, USA). GAPDH was used as the corresponding control. The relative protein expression levels were determined relative to GAPDH.

$m i R$ target prediction. The possible miRs that can target THBS-1 were predicted using miRanda (http://microrna. sanger.ac.uk/), TargetScan (genes.mit.edu/targetscan) and PicTar (http://pictar.mdc-berlin.de).

EGFP reporter assay. INS-1 cells were transfected with miR-182-5p mimics, miR-182-5p inhibitor and reporter vectors 
Table I. Primer sequences used in reverse transcription-quantitative polymerase chain reaction.

\begin{tabular}{ll}
\hline Name & \multicolumn{1}{c}{ Primer sequence } \\
\hline miR-182-5p RT primer & 5'-GTCGTATCCAGTGCAGGGTCCGAGGTGCACT \\
& GGATACGACAAGTGTG-3' \\
U6 RT primer & 5'-GTCGTATCCAGTGCAGGGTCCGAGGTATTCGCA \\
& CTGGATACGACAAAATATGGAAC-3' \\
miR-182-5p forward & 5'-TCGGGTTTGGCAATGGTAGAAC-3' \\
U6 forward & 5'-TGCGGGTGCTCGCTTCGGCAGC-3' \\
Reverse & 5'-CCAGTGCAGGGTCCGAGGT-3' \\
THBS1 forward & 5'-TTTGCTGCGTTTGTGGAA-3' \\
THBS1 reverse & 5'-GAGGAGGTATCTGTAATGC-3' \\
$\beta$-actin forward & 5'-CGTGACATTAAGGAGAAGCTG-3' \\
$\beta$-actin reverse & 5'-CTAGAAGCATTTGCGGTGGAC-3'
\end{tabular}

bearing either THBS 1 3'UTR wild-type or THBS 1 3'UTR mutant-type. An F-4500 fluorescence spectrophotometer (Hitachi, Ltd., Tokyo, Japan) was used to detect the intensities of fluorescence. Red fluorescent protein (RFP) expression vector was used as a reporter control. Relative EGFP fluorescence intensity was normalized to the RFP fluorescence intensity.

Statistical analysis. Data were analyzed using GraphPad Prism 6.0 statistical software (GraphPad Software, Inc., La Jolla, CA, USA) and were presented as the mean \pm standard deviation. A two-tailed Student's t-test was performed to compare differences between two groups. One-way analysis of variance followed by Tukey's post hoc test was used to compare differences between groups. $\mathrm{P}<0.05$ was considered to indicate a statistically significant difference.

\section{Results}

FFA induces cell toxicity in INS-1 cells. To determine the effect of FFA on cell viability and apoptosis, Pal was selected as the FFA. INS-1 cells were cultured and incubated with different concentrations of Pal. The subsequent MTT assay revealed that Pal increased INS-1 cell viability following $8 \mathrm{~h}$ of incubation and significantly decreased cell viability at 24 or $48 \mathrm{~h}$ of incubation. These effects occurred in a dose-dependent manner (Fig. 1A). Results of flow cytometry suggested that incubations for 24 or $48 \mathrm{~h}$ with $\mathrm{Pal}(0.5 \mathrm{mmol} / \mathrm{l})$ increased the cell apoptosis rate by 2.8 - or 3.2- fold, respectively (Fig. 1B). These results suggested that Pal can induce cell toxicity in INS-1 cells.

THBS-1 protects INS-1 cells from Pal-induced cell toxicity. It has previously been indicated that THBS-1 is associated with beta cell function and T2DM (8). To further explore whether THBS-1 is involved in the lipotoxicity of INS-1 cells, the THBS-1 expression plasmid, pcDNA3-THBS-1, was transfected into INS-1 cells, which were incubated with different concentrations of Pal. The efficiency of pcDNA3-THBS 1 was detected by RT-qPCR (Fig. 2A). Data indicated that THBS-1 significantly reversed the changes in cell viability and

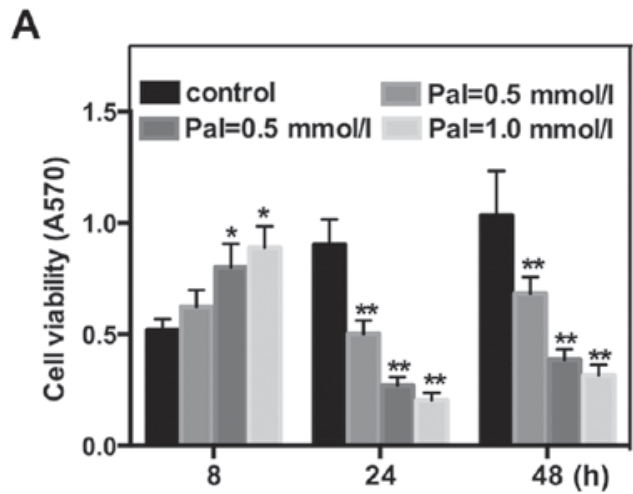

B

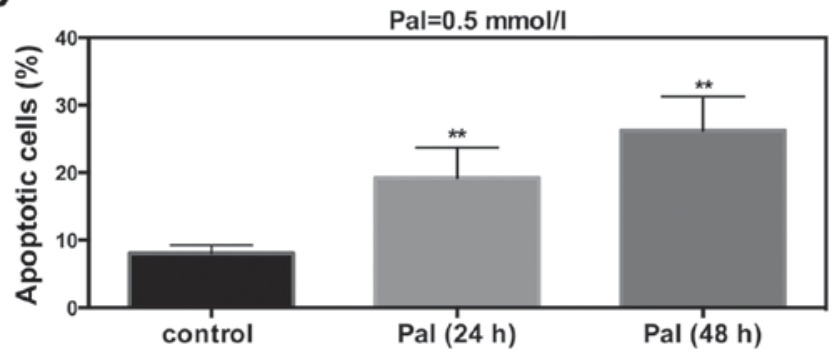

Figure 1. Pal induces cell toxicity in INS-1 cells. INS-1 cells were incubated with different concentrations of Pal $(\mathrm{Pal}=0.25,0.5$, and $1.0 \mathrm{mmol} / \mathrm{l})$ for different lengths of time ( $t=8,24$ and $48 \mathrm{~h})$. The control cells were treated with $\mathrm{NaOH}$. (A) MTT assay was used to detect the effect of Pal on cell viability of INS-1 cells. (B) Flow cytometric analysis using Annexing V-fluorescein isothiocyanate/propidium iodide for the detection of cell apoptosis induced by $\mathrm{Pal}(\mathrm{Pal}=0.5 \mathrm{mmol} / \mathrm{l})$. Data are expressed as the mean \pm standard deviation. ${ }^{*} \mathrm{P}<0.05$ and $^{* *} \mathrm{P}<0.01$ vs. control. Pal, palmitate.

apoptosis that were induced by Pal following incubation for 24 or 48 h. These data suggested that THBS 1 protects INS-1 cells from Pal-induced lipotoxicity (Fig. 2).

Bioinformatics prediction. Previous studies have reported that a number of miRs are involved in regulating the occurrence and progression of T2DM (12-16). To further determine whether THBS-1 is regulated by other molecules in its actions on the lipotoxicity of INS-1 cells, miRanda, Targetscan and PicTar were used to predict the possible miRs that may target 
A

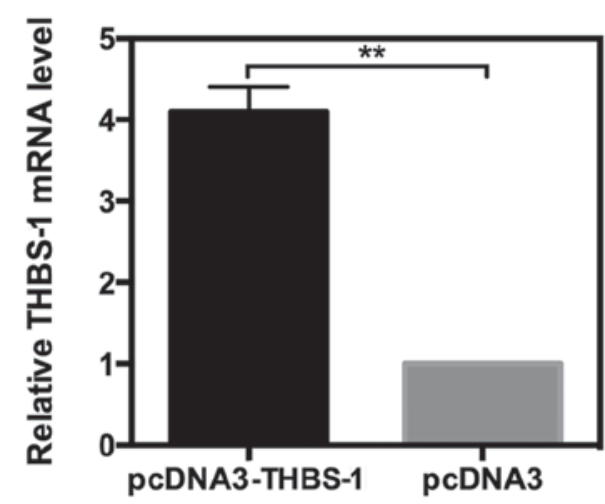

B

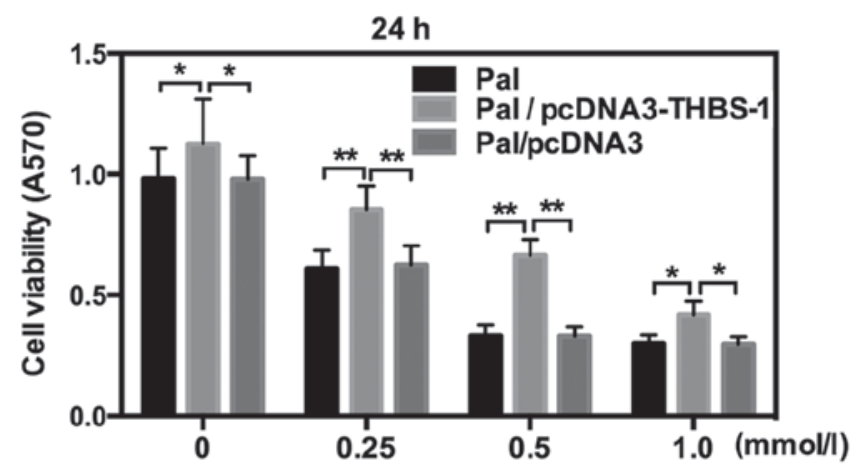

C

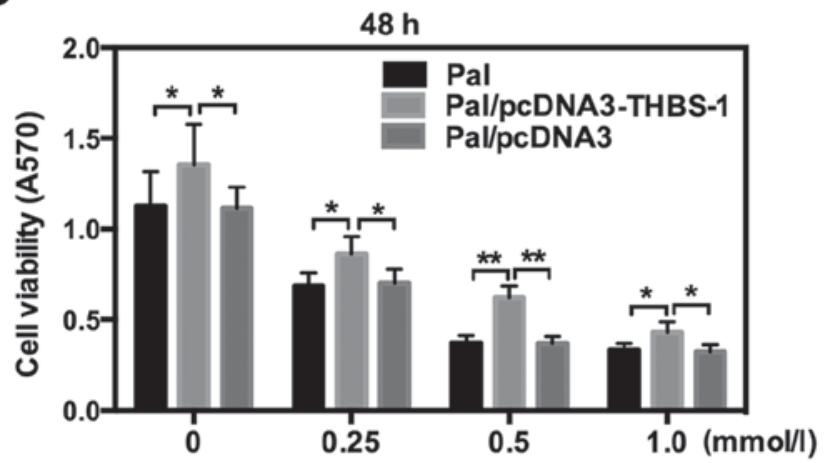

$\mathrm{Pal}=0.5 \mathrm{mmol} / \mathrm{l}$

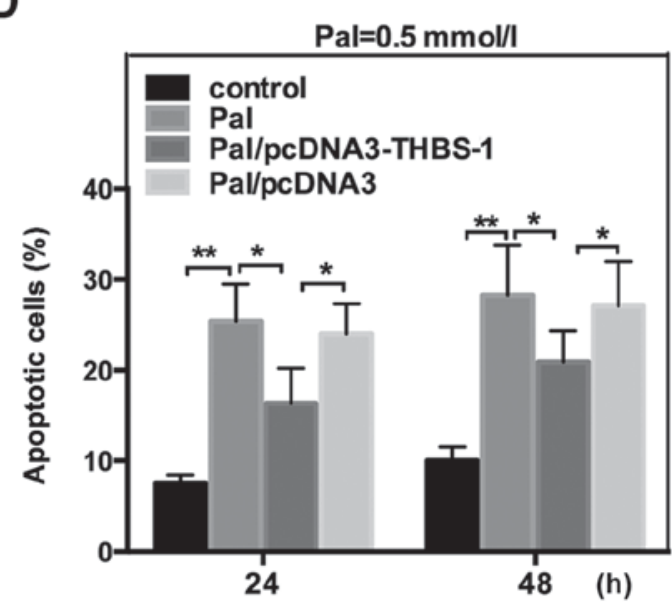

Figure 2. THBS-1 protects INS-1 cells from Pal-induced cell lipotoxicity. INS-1 cells were exposed to different concentrations of Pal (Pal=0, $0.25,0.5$ and $1.0 \mathrm{mmol} / \mathrm{l})$ for different time (t=24 and $48 \mathrm{~h}$ ) either in the presence or absence of THBS-1. (A) The efficiency of pcDNA3-THBS-1 vector. Cell viability was detected by MTT analysis when cells were treated with different concentrations of pal for (B) $24 \mathrm{~h}$ or (C) $48 \mathrm{~h}$ in the absence (Pal) or presence (Pal/pcDNA3-THBS 1) of THBS-1. (D) Cell apoptosis rate was detected by flow cytometric when cells were treated with Pal (Pal=0.5 mmol/1) for 24 or $48 \mathrm{~h}$ with or without THBS-1. Data are expressed as the mean \pm standard deviation. ${ }^{*} \mathrm{P}<0.05$ and ${ }^{* *} \mathrm{P}<0.01$ vs. control. THBS-1, thrombospondin 1 ; Pal, palmitate.

THBS-1. The prediction results from these bioinformatics software were combined and several miRs were selected. Among these, miR-182-5p was of interest. To the best of our knowledge, miR-182-5p has not been reported to be associated with T2DM. A total of 7 bases from the 3'-UTR region of THBS-1 were identified to be complementary to the seed sequence of miR-182-5p (Fig. 3). Considering these observations, miR-182-5p was selected for further study.

miR-182-5p directly targets the 3'-UTR of THBS-1 and downregulates its expression. miRs are well known to exert their function by targeting the 3'-UTR of target genes. To determine whether or not miR-182-5p directly targets THBS-1, EGFP reporter analysis was performed. Reporter vectors bearing either wild-type or mutant-type THBS-1 3'-UTR were co-transfected with miR-182-5p mimics or inhibitor into INS-1 cells. The efficiency of miR-182-5p mimics and inhibitors were detected by RT-qPCR (Fig. 4A). The fluorescence intensity of each group was measured and the results indicated miR-182-5p decreased the intensity of wild-type 3'-UTR by $\sim 69 \%$, while the intensity of the wild-type 3'-UTR was increased by $\sim 1.8$-fold when miR-182-5p was inhibited. However, the intensity of mutant-type 3'-UTR was not significantly affected when miR-182-5p was overexpressed or inhibited (Fig. 4B).

The majority of miRs can negatively regulate their target genes by targeting the 3'-UTR. To further determine the regulation mode of miR-182-5p in the present study, RT-qPCR and western blot analysis were performed. The results demonstrated that miR-182-5p mimics decreased the mRNA and protein expression level of THBS-1 by $\sim 65$ or $70 \%$, respectively, whereas the expression of THBS-1 was significantly increased by $\sim 1.8$ - or 2.5 -fold when miR-182-5p was inhibited (Fig. 4C and D). These results suggested that miR-182-5p can directly bind to the 3 '-UTR of THBS-1 and negatively regulate its expression at mRNA and protein levels.

Upregulation of miR-182-5p in Pal-treated cells. The aforementioned results indicated that miR-182-5p could target THBS-1 in INS-1 cells. To further investigate whether or not miR-182-5p was involved in Pal-induced cytotoxicity, RT-qPCR was used to detect the alteration in miR-182-5p expression in response to Pal. INS-1 cells were incubated with Pal $(0.5 \mathrm{mmol} / \mathrm{l})$ for $24 \mathrm{~h}$. The results of RT-qPCR indicated that miR-182-5p expression level was increased by 1.7 -fold in Pal-amended cells compared with the control cells (Fig. 5). 


\section{Position 38-44 of THBS1 3' UTR 5' ...ACUGAUCAUAAACCAAUGCUGGU... hsa-miR-338-3p 3' GUUGUUUUAGUGACUACGACCU}

Figure 3. miR-182-5p could target the 3'-UTR of THBS 1. miRanda, Targetscan and PicTar were used to predict the possible miRs which could target THBS 1. The potential binding site for miR-182-5p in the 3'-UTR of THBS-1 mRNA was indicated. UTR, untranslated region; THBS-1, thrombospondin 1; miR, microRNA.

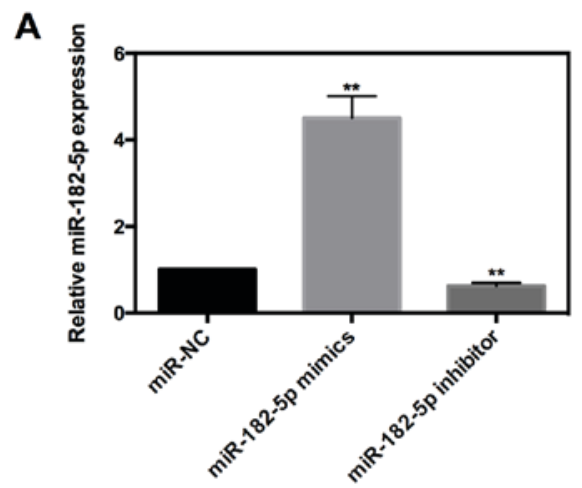

C

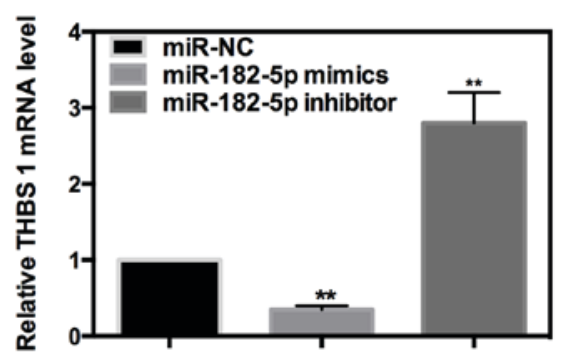

B

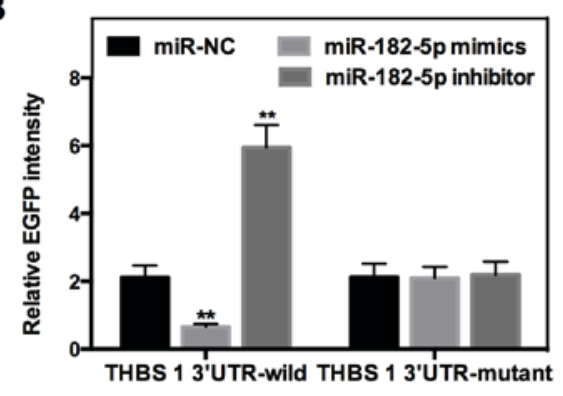

D

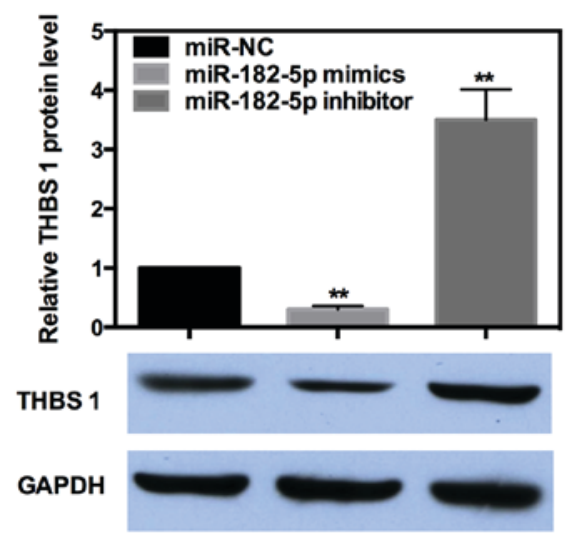

Figure 4. miR-182-5p directly targets the 3'-UTR of THBS-1 and downregulate its expression. (A) The efficiency of miR-182-5p mimics and inhibitors. (B) EGFP reporter analysis was performed to detect the EGFP intensity after the wild- or mutant-type of 3'-UTR was cotransfected with miR-182-5p mimics, miR-182-5p inhibitor or miR-NC in INS-1 cells. EGFP intensity was normalized to the red fluorescent protein fluorescence intensity. (C) Reverse transcription-quantitative polymerase chain reaction analysis was used to detect the mRNA expression of THBS 1 when the expression of miR-182-5p was altered. $\beta$-actin was used as the corresponding control. The relative mRNA expression of miR-NC group was normalized as 1. (D) Western blot analysis was used to detect the relative protein expression level of THBS 1 when miR-182-5p was overexpressed or inhibited. The relative protein expression was determined as the ratio to GAPDH. Relative protein expression of miR-NC group was normalized as 1 . Data are expressed as the mean \pm standard deviation. ${ }^{* *} \mathrm{P}<0.01 \mathrm{vs}$. miR-NC. miR, microRNA; UTR, untranslated region; THBS-1, thrombospondin 1; NC, negative control; EGFP, enhanced green fluorescent protein.

This result suggested that miR-182-5p may serve a role in Pal-induced lipotoxicity in INS-1 cells.

miR-182-5p promotes Pal-induced lipotoxicity of INS-1 cells by directly targeting THBS-1. To determine the exact effect of miR-182-5p on Pal-induced cytotoxicity in INS-1 cells, MTT and flow cytometric analysis were also performed. As indicated in Fig. 6, miR-182-5p mimics significantly decreased THBS-1 cell viability (Fig. 6A and B), while increasing Pal-induced apoptosis in INS-1 cells following incubation with Pal (Fig. 6C). However, the cell viability was increased (Fig. 6A and B) and Pal-induced apoptosis was decreased (Fig. 6C) in cells that were transfected with miR-182-5p inhibitors. To further confirm that miR-182-5p affected Pal-induced lipotoxicity by regulating THBS-1 directly, a rescue experiment was performed. miR-182-5p and THBS-1 expression plasmid without the 3'-UTR (pcDNA3-THBS 1) were co-transfected

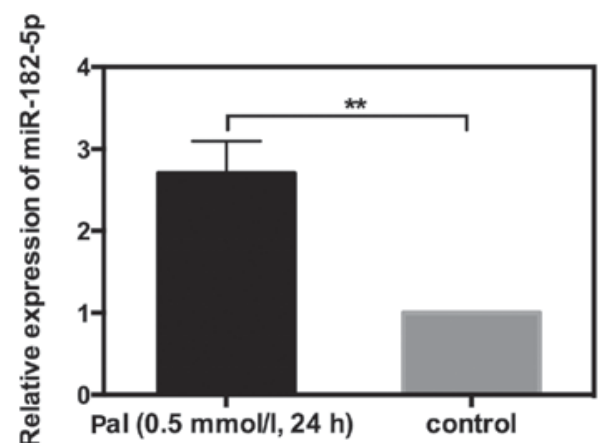

Figure 5. miR-182-5p is upregulated in Pal-amended cells. Reverse transcription-quantitative polymerase chain reaction was performed to detect the expression level of miR-182-5p when INS-1 cells was treated with Pal (Pal=0.5 mmol/l) for $24 \mathrm{~h}$. U6 was used as the corresponding control. The relative expression of control group was normalized to 1. Data are expressed as the mean \pm standard deviation. ${ }^{* *} \mathrm{P}<0.01$ as indicated. miR, microRNA; Pal, palmitate. 
A

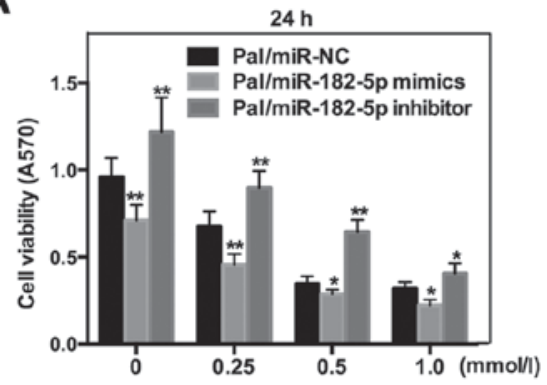

D

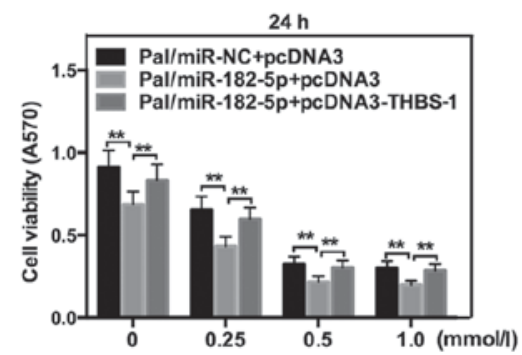

B

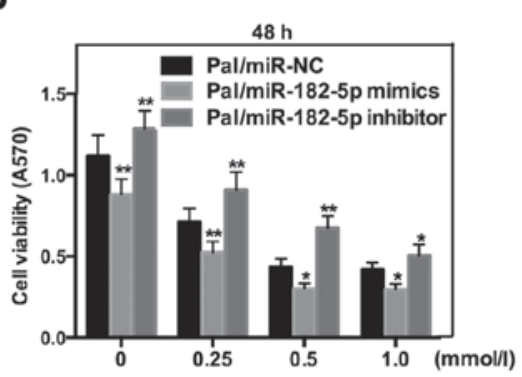

E

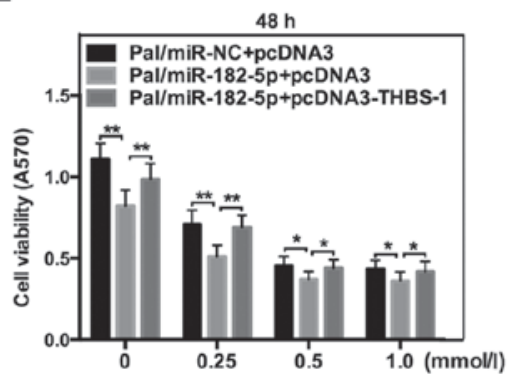

C

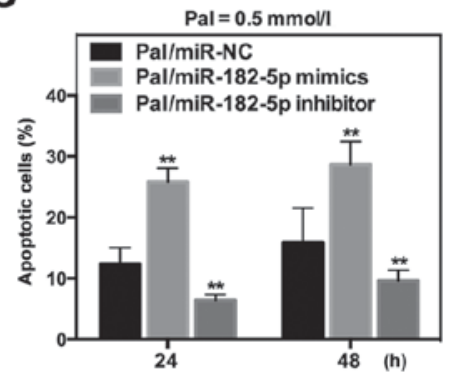

$\mathbf{F}$

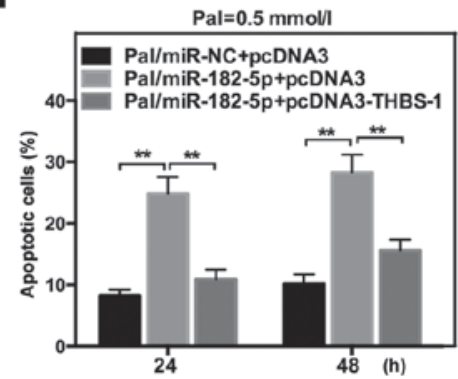

Figure 6. miR-182-5p promotes Pal-induced lipotoxicity of INS-1 cells by directly targeting THBS-1. (A and B) MTT analysis was used to detect the cell viability of palmitate-amended INS-1 cells when miR-182-5p was overexpressed or inhibited. Data are expressed as the mean \pm standard deviation. (C) Cell apoptosis rate was detected in Pal-treated cells when the expression of miR-182-5p was altered. ${ }^{*} \mathrm{P}<0.05$ and ${ }^{* *} \mathrm{P}<0.01 \mathrm{vs}$. Pal/miR-NC. (D and E) Restoration of THBS-1 counteracted the effect of miR-182-5p on cell viability of Pal-treated INS-1 cells. (F) Ectopic expression of THBS 1 neutralized the alteration of cell apoptosis rate induced by miR-182-5p. ${ }^{*} \mathrm{P}<0.05$ and ${ }^{* *} \mathrm{P}<0.01$ as indicated. miR, microRNA; Pal, palmitate.

into INS-1 cells. As expected, overexpression of THBS-1 counteracted the effect of miR-182-5p on cell viability (Fig. 6D and E) and apoptosis (Fig. 6F). Taken together, these results indicated that miR-182-5p affects Pal-induced lipotoxicity by directly regulating THBS-1.

\section{Discussion}

More than 415 million people worldwide are estimated to have diabetes, with an ever-increasing morbidity and mortality (21). It is reported that $\sim 95 \%$ of all diabetes cases are T2DM $(22,23)$. T2DM is a complex disorder characterized by insulin resistance and defects in pancreatic beta cell function. Numerous experiments have reported that the failure of beta cells to increase mass and function is central in T2DM $(24,25)$. Nutrients are essential for the maintenance of beta cell function and mass. However, an excess of nutrients such as glucose or FFAs can induce injurious effects on beta cell mass and function that contribute toward the progressive loss of functional beta cell mass (26).

In the present study, Pal, which was used as an FFA, increased INS-1 cell viability after a short exposure time $(8 \mathrm{~h})$. However, Pal significantly decreased cell viability following 24 or 48 h of incubation. These results indicated that FFAs exert stimulatory effects acutely, but inhibitory effects chronically on beta cell survival. The subsequent flow cytometry assay suggested that $\mathrm{Pal}(0.5 \mathrm{mmol} / \mathrm{l})$ markedly increased the cell apoptosis rate following 24 or $48 \mathrm{~h}$ of exposure.

THBS-1 is a multifunctional glycoprotein released from various types of cell and exerts its diverse biological effects through binding to extracellular matrix proteins and cell surface receptors (8). Recent studies have suggested that
THBS-1 is involved in the pathogenesis of insulin resistance and is important for beta cell function $(27,28)$. However, the exact effect of THBS 1 on FFA-induced lipotoxicity is not thoroughly understood. The present study revealed that THBS-1 significantly reversed the changes of cell viability and apoptosis that were induced by Pal exposure. These results suggested that THBS-1 can protect INS-1 cells from Pal-induced lipotoxicity.

Additionally, the precise mechanisms of THBS-1 that caused lipotoxic effects, and whether or not THBS-1 is regulated by other molecules, were further investigated. In recent years, it has been determined that an increasing number of miRs participate in various pathological processes (29-31), including lipotoxicity $(32,33)$. Subsequent experiments focused on the potential participation of miRs in Pal-induced lipotoxicity. To begin with, combining the prediction results of three bioinformatic analyses, miR-182-5p was selected. To further identify whether or not miR-182-5p directly targets THBS-1, an EGFP reporter assay was performed, which revealed that miR-182-5p could negatively regulate the intensity of wild-type 3'-UTR. However, miR-182-5p could not affect the intensity of mutant-type 3'-UTR. Furthermore, miR-182-5p was indicated to negatively regulate the expression of THBS-1 at the mRNA and protein levels.

The aforementioned results have indicated that miR-182-5p could target THBS-1 in INS-1 cells. To further investigate whether or not miR-182-5p was involved in Pal-induced cytotoxicity, miR-182-5p expression was increased in Pal-amended cells and it was hypothesized that miR-182-5p may participate in Pal-induced lipotoxicity. The subsequent cell phenotype experiments suggested that miR-182-5p decreased cell viability and increased Pal-induced apoptosis in INS-1 cells that were incubated with Pal. To further confirm that THBS-1 was a 
direct functional target gene of miR-182-5p, a rescue experiment was designed. The results suggested that restoration of THBS- 1 could counteract the effects of miR-182-5p on cell viability and apoptosis. Taken together, the results of the present study suggested that miR-182-5p affects Pal-induced cell viability and apoptosis by directly targeting THBS-1.

In conclusion, the present findings suggested that THBS-1 can protect INS-1 cells from FFA-induced lipotoxicity. Furthermore, miR-182-5p, which is able to directly target the 3'-UTR of THBS-1, can increase FFA-induced cytotoxicity. These findings demonstrated that miR-182-5p may be useful for identifying novel therapeutic approaches that may improve beta cell mass and function. Additionally, miR-182-5p may be a novel biomarker for the pathogenesis and progression of T2DM.

\section{Acknowledgements}

Not applicable.

\section{Funding}

No funding was received.

\section{Availability of data and materials}

The datasets used and/or analyzed during the present study are available from the corresponding author on reasonable request.

\section{Authors' contributions}

RB conceived and designed the study, acquired data and had an important role in interpreting the results. LY performed the experiments, contributed significantly to analysis and manuscript preparation. DJ assisted in performing the data analysis with constructive discussions. All authors read and approved the final manuscript.

\section{Ethics approval and consent to participate}

Not applicable.

\section{Patient consent for publication}

Not applicable.

\section{Competing interests}

The authors declare that they have no competing interests.

\section{References}

1. Camlio A, Cecilia SP, Valeria H and Marcos S: Analysis of the relationship between the referral and evolution of patients with type 2 diabetes mellitus. Int J Environ Res Public Health 15: 1534,2018

2. Mashitisho ML and Mashitisho BG: Early insulin therapy in patients with type 2 diabetes mellitus. J Endocrinol Metab Diab South Africa 21: 13-15, 2016

3. Gu J, Wei Q, Zheng H, Meng X, Zhang J and Wang D: Exendin-4 promotes survival of mouse pancreatic $\beta$-cell line in lipotoxic conditions, through the extracellular signal-related kinase 1/2 pathway. J Diabetes Res 2016: 5294025, 2016.
4. Good DJ, Polverini PJ, Rastinejad F, Le Beau MM, Lemons RS, Frazier WA and Bouck NP: A tumor suppressor-dependent inhibitor of angiogenesis is immunologically and functionally indistinguishable from a fragment of thrombospondin. Proc Nat Acad Sci USA 87: 6624-6628, 1990.

5. Adams JC and Lawler J: The thrombospondins. Int J Biochem Cell Biol 36: 961-968, 2004.

6. Savill J, Fadok V,Henson P and Haslett C: Phagocyte recognition of cells undergoing apoptosis. Immunol Today 14: 131-136, 1993.

7. Ribeiro SM, Poczatek M, Schultz-Cherry S, Villain M and Murphy-Ullrich JE: The activation sequence of thrombospondin-1 interacts with the latency-associated peptide to regulate activation of latent transforming growth factor-beta. J Biol Chem 274: 13586-13593, 1999.

8. Matsuo Y,Tanska M, Yamakage H, Sasaki Y, Muranaka K, Hata H, Ikai I, Shimatsu A, Inoue M, Chun TH and Satoh-Asahara N: Thrombospondin 1 as a novel biological marker of obesity and metabolic syndrome. Metabolism 64: 1490-1499, 2015.

9. Delić D, Eisele C, Schmid R, Baum P, Wiech F, Gerl M, Zimdahl H, Pullen SS and Urquhart R: Urinary exosomal miRNA signature in type II diabetic nephropathy patients. PLoS One 11: e0150154, 2016

10. Olerud J, Mokhtari D, Johansson M, Christoffersson G, Lawler J, Welsh N and Carlsson PO: Thrombospondin-1: An islet endothelial cell signal of importance for $\beta$-cell function. Diabetes 60: 1946-1954, 2011.

11. Fu X, Li Y, Alvero A, Li J, Wu Q, Xiao Q, Peng Y, Hu Y, Li X, Yan W, et al: MicroRNA-222-3p/GNAI2/AKT axis inhibits epithelial ovarian cancer cell growth and associates with good overall survival. Oncotarget 7: 80633-80654, 2016

12. Li Y,Zhang T, Zhou Y, Sun Y, Cao Y, Chang X, Zhu Y and Han X: A presenilin/Notch1 pathway regulated by miR-375, miR-30a, and miR-34a mediates glucotoxicity induced-pancreatic beta cell apoptosis. Sci Rep 6: 36136, 2016.

13. Chen X, Shi C, Wang C, Liu W, Chu Y, Xiang Z, Hu K, Dong P and Han X: The role of miR-497-5p in myofibroblast differentiation of LR-MSCs and pulmonary fibrogenesis. Sci Rep 7: 40958, 2017.

14. Lin X, Guan H, Huang Z, Liu J, Li H, Wei G, Cao X and Li Y: Downregulation of $\mathrm{Bcl}-2$ expression by miR-34a mediates palmitate-induced Min6 cells apoptosis. J Diabetes Res 2014: 258695, 2014

15. Li Y, Xu X, Liang Y, Liu S, Xiao H, Li F, Cheng H and Fu Z: miR-375 enhances palmitate-induced lipoapoptosis in insulin-secreting NIT-1 cells by repression myotrophin (V1) protein expression. Int J Clin Exp Pathol 3: 254-264, 2010.

16. Lovis P, Roggli E, Laybutt DR, Gattesco S, Yang JY, Widmann C, Abderrahmani A and Regazzi R: Alterations in microRNA expression contribute to fatty acid-induced pancreatic beta-cell dysfunction. Diabetes 57: 2728-2736, 2008.

17. Yao J, Xu C, Fang Z, Li Y, Liu H, Wang Y, Xu C and Sun Y: Androgen receptor regulated microRNA miR-182-5p promotes prostate cancer progression by targeting the ARRDC3/ITGB4 pathway. Biochem Biophys Res Commun 474: 213-219, 2016.

18. Jiang W, Liu G and Tang W: MicroRNA-182-5p ameliorates liver ischemia-reperfusion injury by suppressing Toll-like receptor 4 . Transplant Proc 48: 2809-2814, 2016.

19. Blume CJ, Hotz-Wagenblatt A, Hüllein J, Sellner L, Jethwa A Stolz T, Slabicki M, Lee K, Sharathchandra A, Benner A, et al: p53-dependent non-coding RNA networks in chronic lymphocytic leukemia. Leukemia 29: 2015-2023, 2015.

20. Livak KJ and Schmittgen TD: Analysis of relative gene expression data using real-time quantitative PCR and the 2(-Delta Delta C(T)) method. Methods 25: 402-408, 2001.

21. International Diabetes Federation. IDF diabetes atlas. 7. Brussels: International Diabetes Federation. 2015.

22. American Diabetes Association: Diagnosis and classification of diabetes mellitus. Diabetes Care 36(Suppl 1): S67-S74, 2013.

23. American Diabetes Association: Diagnosis and classification of diabetes mellitus. Diabetes Care 37(Suppl 1): S81-S90, 2014.

24. Prentki $M$ and Nolan CJ: Islet beta cell failure in type 2 diabetes. J Clin Invest 116: 1802-1812, 2006.

25. Hull RL, Kodama K, Utzschneider KM, Carr DB, Prigeon RL and Kahn SE: Dietary-fat-induced obesity in mice results in beta cell hyperplasia but not increased insulin release: Evidence for specificity of impaired beta cell adaptation. Diabetologia 48: 1350-1358, 2005.

26. Poitout V, Amyot J, Semache M, Zarrouki B, Hagman D and Fontés G: Glucolipotoxicity of the pancreatic beta cell. Biochim Biophys Acta 1801: 289-298, 2010. 
27. Inoue $M$, Jiang $Y$, Barnes RH II, Tokunaga $M$, Martinez-Santibañez G, Geletka L, Lumeng CN, Buchner DA and Chun TH: Thrombospondin 1 mediates high-fat diet-induced muscle fibrosis and insulin resistance in male mice. Endocrinology 154: 4548-4559, 2013.

28. Kong P, Gonzalez-Quesada C, Li N, Cavalera M, Lee DW and Frangogiannis NG: Thrombospondin-1 regulates adiposity and metabolic dysfunction in diet-induced obesity enhancing adipose inflammation and stimulating adipocyte proliferation. Am J Physiol Endocrinol Metab 305: E439-E450, 2013.

29. Terracciano D, Terreri S, de Nigris F, Costa V, Celin GA and Cimmino A: The role of a new class of long noncoding RNAs transcribed from ultraconserved regions in cancer. Biochim Biophys Acta Rev Cancer 1868: 449-495, 2017.
30. Yin J, Ren W, Huang X, Li T and Yin Y: Protein restriction and cancer. Biochim Biophys Acta Rev Cancer 1869: 256-262, 2018.

31. Zhi F, Shao N, Xue L, Xu Y, Kang X, Yang Y and Xia Y Characteristic microRNA expression induced by $\delta$-opioid receptor activation in the rat liver under prolonged hypoxia. Cell Physiol Biochem 44: 2296-2309, 2017.

32. Cazanave SC, Mott JL, Elmi NA, Bronk SF, Masuoka HC, Charlton MR and Gores GJ: A role for miR-296 in the regulation of lipoapoptosis by targeting PUMA. J Lipid Res 52: 1517-1525, 2011.

33. Han YB, Wang MN, Li Q, Guo L, Yang YM, Li PJ, Wang W and Zhang JC: MicroRNA-34a contributes to the protective effects of glucagon-like peptide-1 against lipotoxicity in INS-1 cell. Chin Med J (Engl) 125: 4202-4208, 2012. 